\title{
Building trust and recovery capital: the professionals' helpful practice
}

\author{
Alain Topor, Lisa Skogens and Ninive von Greiff
}

\author{
Alain Topor is based at the \\ Department of Social Work, \\ Stockholm University, \\ Stockholm, Sweden. \\ Lisa Skogens and Ninive von \\ Greiff are Associate Professors \\ at the Department of Social \\ Work, Stockholm University, \\ Stockholm, Sweden.
}

\begin{abstract}
Purpose - The possibility of recovery for persons with co-occurring addiction and mental health problems has been contested. Though, recent studies show that recovery might happen, but without connection to specific treatment interventions. The purpose of this paper is to analyse professionals' perceptions of their contribution to improvement.

Design/methodology/approach - In all, 15 experienced professionals were interviewed. The interviews were analysed using thematic analysis.

Findings - Recovery processes were dependent of the persons' access to different forms of recovery capital $(R C)$. Lack of $R C$ was often associated with lack of trust in one's self and others (identity and personal capital). Professionals had to be accepted as trustful agents through co-creating changes in the person's life. Trusting a professional might be a basis for trusting one's self as an agent in one's recovery process and develop a social network (identity and relationship capital). Other aspects stressed by the professionals were to manage their own fragmentized organisations and societal shortcomings (economic capital).

Practical implications - Recovery has been described as a profoundly individual journey. However, it is also deeply social, involving other persons and contextual factors. Focusing on just one level might counteract the complex work behind double recovery.

Originality/value - Improvement was described as dependent on the presence of personal, inter-personal, organisational and societal factors. The findings give a deep and concrete understanding of the process constituting the development of a working alliance and its dependence on factors outside the direct relation between the staff member and the person.
\end{abstract}

Keywords Trust, Mental health, Professionals, Addiction, Recovery capital, Double recovery

Paper type Research paper

\section{Introduction}

Mental health and alcohol and drug (AOD) problems have been, and sometimes still are, considered as chronic illnesses. Periods without symptoms or drug use have been defined as temporary periods of remission, with the illness still present and with relapses as part of the natural course of the illness (Bleuler, 1950). Persons with co-occurring AOD and mental health problems have been considered as struggling against double troubles (Davidson et al., 2008) and thus, as having even more limited possibilities to recover (Davidson and White, 2007).

The notion of recovery was introduced in the mental health field during the second part of the last century (Warner, 1985/2004). Clinical recovery could be total (no symptoms, no treatment and a normal social life) or social (including the continued presence of symptoms and of community-based interventions, but without hindering a normal social life). The possibility of recovery has even become accepted regarding problems with (AOD) (Blomqvist, 1996). Lately, the concept of "double recovery" was introduced regarding persons with "double troubles" (Davidson et al., 2008).

Researchers and persons with their own experience of mental health problems have developed the notion of recovery into "personal recovery", defined as a process leading to a satisfactory life, and including a sense of agency even in the presence of substance use or clinical symptoms 
(Bellack, 2006; Farkas, 2007; Watson and Rollins, 2015). Irrespective of the different definitions, it has not been possible to connect recovery to specific professional methods when it comes either to AOD or to severe mental problems and thus to co-occurring problems (Elison et al., 2016).

Recent studies have turned to the experiences of users, social networks and professionals as important contributions to our knowledge about professional interventions' role for improvement (Orford et al., 2006), and about "extra-treatment change generating factors" (p. 67). A paradoxical finding in the mental health field is that even if no specific treatment has been found to be more effective than others are.

\section{Helpful professionals}

Users have stressed the helpful role of certain professionals, independently of their profession (Ljungberg et al., 2015). Central components in building helpful relationships were inter-personal continuity, emotional climate and social interaction. Furthermore, components of helping relationships were a non-stigmatizing attitude on the part of the professionals, and their willingness to work outside established routines (Denhov and Topor, 2012). Regarding the contribution of professionals to the improvement of persons suffering from mental health and AOD problems, users emphasised the importance of being regarded as human beings (Cruce et al., 2012). Individualised interventions and not standardized care (Cruce et al., 2012; Hipolito et al., 2011; Ness et al., 2014) and autonomy, self-determination and the person's expertise expressed in a collaborative approach and shared decisions about adapted interventions (Cruce et al., 2012; Ness et al., 2014) were also mentioned. Professionals could help the persons by conveying their hope about the future (Cruce et al., 2012; Sælør et al., 2015) and by providing help with the challenges of everyday life (Ness et al., 2014; Watson and Rollins, 2015). Finally, they could help the persons by eliminating or bridging over fragmentized treatment and support systems (Ness et al., 2014). Clients in von Greiff and Skogens' (2014) study stressed the importance of structure and regularity.

\section{The professionals' experiences}

Studying professionals' helpful practice, from the professionals' perspective, Ness et al. (2017) mentioned the importance of collaborative practices based "on the idea that service users are first and foremost (struggling) human beings [...]" (p. 6) with their own expertise. Professionals described themselves sometimes as advocates for service users in relation to the organisation they were part of. In Sælør et al. (2015), professionals stressed the importance of them nourishing their own hope to be able to communicate it to the persons they were working with and thus create a collaborative relationship.

Practitioners emphasised the importance of working with practical everyday aspects of the users' life, primarily financial matters and housing (Ness et al., 2017; Sælør et al., 2015; Skogens and von Greiff, 2014; Watson and Rollins, 2015). In von Greiff and Skogens (2014), staff also mentioned the clients' motivation to change, working with the person's sense of guilt and shame, and creating a working alliance through knowledge transmission.

\section{Aim}

The aim of the present study was to gather and analyse professionals' experience-based knowledge about their own contribution to improvement for persons with co-occurring AOD and mental health problems.

\section{Method}

In all, 15 professionals were interviewed about their experiences of their own contribution to the improvement process for persons with co-occurring $A O D$ and mental health problems. In Sweden, persons with AOD problems are primarily taken care of by the social services, except for de-intoxication and substitution treatment. The interviewees worked in different services in the Stockholm region. 
Institutions within these services as well as user organisations and community-based services were contacted and received a presentation of the study. The final decision to participate in the interview was left to the individual staff members. The selection criterion was having consistent and actual experience of working with persons with co-occurring mental health and AOD problems. Staff members interested in participating were asked to contact the research team and were given additional information. Before being interviewed, they were asked to complete an informed participation schedule.

Four men and 11 women, aged between 39 and $61(m=51)$ were interviewed. They had between 8 and 28 years $(m=16)$ of experience working with persons with co-occurring problems. They had diverse professional backgrounds such as social worker, doctor, home helper, nurse and unskilled nurse.

They worked in different roles in nine different services such as residential facilities, supported housing at persons own home, social cooperatives and specialized treatment teams. Thus, they worked with persons with different combinations of AOD and mental health problems, at different stages of the persons' life histories and recovery process.

The data collection and transcription were based on the methodology developed by Orford et al. (2006). The interviews were conducted as "focused conversations" (Ness et al., 2017) about the participants' own experiences of being helping persons in a recovery process. Recovery was defined in terms of "personal recovery". The role of the interviewer was to obtain detailed and concrete descriptions of the professionals' "practices in context" (Bertaux, 1997). The interviews lasted between 30 minutes and one hour and took place at the professionals' work place or at the department of social work. They were audio-recorded and reports using the persons' own words were written subsequently by another research team member and finally reviewed against the recorded interview by the interviewer. Small talk were excluded. The three authors conducted interviews and wrote reports.

The reports were analysed according to Thematic Analysis as described in Braun and Clarke (2006). The reports were read several times by the research group and preliminary themes were identified inductively. The first author went on re-reading the reports and began to develop the themes discussed in the group, going back and forth between the reports and the emerging themes. Excerpt from the reports were then grouped under the different themes, leading to both the integration of preliminary themes and the creation and naming of new themes. The emerging themes were discussed on several occasions in the research team. Illustrative excerpts from the interviews were chosen and integrated into the presentation of the findings.

The study was approved by the Regional Ethical Review Board in Stockholm (No. 2016/269-31/5).

\section{Findings}

Four themes emerged; "A base to build upon", "Building trust", "Managing a fragmentized organisation", and "The importance of societal conditions". A recurring concept in the interviews was "alliance"; building a positive relationship between the person and the professional involved in a co-productive project:

The encounter, the interaction and a good alliance are important. We work a lot to help the person to feel seen and heard. The person must have the possibility to participate and decide. The planning gives

a direction, but the alliance is the most important. The alliance is $90 \%$ and the plan $10 \%$ (IP1).

Thus, improvement was described as dependent on the presence of personal, inter-personal, organisational, and societal factors.

\section{A base to build upon}

Building an alliance was described as dependent on the other person's will and capacity to be part of such a mutual relationship. The person in double recovery has a history including experiences that might have a facilitating or hindering role for his/her capacity and preparedness to build reciprocal relationships and thus for his/her improvement. 


\section{Previous experiences of relationships}

How to build a helpful relationship was dependent on the person's background, principally his/ her previous experiences of trustful relationships and of "normality":

Persons that leave our services have some earlier experience of self-confidence in themselves. There is some discrepancy between how it is now and how it has been in the past. Something worked for them earlier and it creates a discomfort; "I do not want it to be like this!" This is something we can use to help the person (IP5).

Working with somebody lacking experience of reciprocal trust was described as a different challenge than developing trust with someone having experienced it.

\section{Social network}

Part of this personal background could still be present, mostly in the form of supporting family members or other social networks to (re)connect to:

Families are an important protecting factor. A social network might be there from the beginning, or it can be developed. It becomes like a family, a network which one can go to and feel at home. Persons in the network can help with finding a job or a suitable activity, and they have connections to others (IP15).

But users may lack such supportive environments. They may even have experienced mostly destructive relationships with family members. Consequently, "[...] they do not want to meet their family" (IP15). In those cases, it becomes important to connect the person to new social networks including persons without actual addiction or mental health problems.

The previous and current presence of supportive persons was presented as an important factor determining the support to be offered by the professional.

\section{Psychiatric diagnosis}

Certain psychiatric diagnoses, usually neuropsychiatric disorders, were mentioned as influencing negatively on the person's capacity to build an alliance. Irrespective of specific diagnoses, the cognitive capacity of the person was also mentioned as being a hindering factor. These difficulties had to be taken into account when working to create an alliance:

A lot have neuropsychiatric disorders. When we meet a person with this diagnosis we have to think how we can help him; you have to be as you are; as a human being (IP6).

Generally, the interviewees seemed to accept the official division of responsibilities for treatment interventions between social and psychiatric services. "Disease", referring to some specific diagnosis such as neuropsychiatric disorders and bipolar disorders, necessitate medical interventions as a precondition to establish a sustainable helpful relationship. Also crisis situations were commonly referred to psychiatric services. On the contrary, "mental health" issues and the persons' endeavours to ameliorate their sense of self were considerate as part of the social services' mission. Clearly, improvements in the person's trust in him/herself and in his/her living conditions could influence their mental health:

Trust creates positive energy, so they can start to change. It contributes to a feeling that change is possible. But, you cannot ignore medication, especially for persons with a bipolar diagnosis (IP8).

\section{Building trust}

The above mentioned factors constitute a heritage that the person and the professional have to deal with. They define the primary goal of building or rebuilding a positive sense of self and of others. They also influence the means available to facilitate this process.

Improving the persons' sense of self was considered as the main strategic goal of the professionals' efforts. For persons with a prior experience of trustful relations, the challenge was about strengthening, rebuilding and reconnecting to social contexts and to supportive relations. Trust between the person and the professional grew when this work was done as a co-construction. 
For persons lacking such psychosocial heritage, the professionals described the establishment of trust as a two-step journey. It consisted, as a first step, of building the person's trust in the professional and, as a second step, building his or her trust in himself/herself.

In both cases, acceptance, accountability, and trusting the professional and oneself had a central role, but had to be co-created, sometimes in different ways.

\section{Acceptance}

Acceptance of the person was mentioned by most of the interviewees as a first step to establishing trust, but it was also more than mere acceptance. Analysing the content of "acceptance" showed that it was not only used for "seeing and accepting the person" behind the $\mathrm{AOD}$ and mental health problems. Accepting the person also meant to recognise and include problematic aspects of the persons' life:

Does it work to accept them as they are? Not if you cannot make a positive spin. You have to see the positive aspects and strengthen them. But if they have a lot of criminality, then you can talk of them as entrepreneurs and about how they could use their skills in another way. Look at them as intelligent and full of energy. It is important to lessen feelings of guilt and shame (IP14).

A recurring paradox was mentioned that concerned acceptance of the person, as this was also described as a way to contribute to changes in this same person:

When they do realize that there is no one here who wants to correct their behavior, then our relation

might be calm. This is when things might start to happen. It goes in the right direction (IP10).

Acceptance of the person meant not reducing the person to a drug addict and a mental patient, but seeing beyond these aspects without negating them. However, mere acceptance was not enough.

\section{Accountability}

Acceptance of the person was described as the first step in the professionals' attempt to establish the basis of a relationship. The second step in this process was the development of an experience of the professional's accountability; the professional proving the existence of a connection between his/her words and actions. This was particularly important and demanding with persons lacking previous experience of trustful relationships:

To create trust, it is important to be predictable. We do what we say. We follow-up what we have done and show curiosity about and interest in the person. We do not judge them, even if that is not always so easy. They have to feel that we see and respect them (IP15).

A second paradox in the interviewees' descriptions of their work may be visible here. It seemed to be necessary that the person wanted change to happen, but the professional sometimes had to be the active, initiative-taking partner. At the same time, the professionals stressed the importance of anchoring the initiatives in the person and his/her sometimes unclear and fragile agenda and will to change.

Even when the person expressed a will to change, the professional might have to become a lobbyist for different possible steps on the road to change. It seems that the mere presence of the professional with the person in different settings could form the basis for common experiences creating trust:

[...] to try to accept and make them change, which they want. It is about tempting them and following them to an open AA-meeting, or to their general practitioner. You have to be very active in the beginning, offering changes (IP8).

\section{To trust a professional}

For persons starting their recovery journey with access to an informal social network and its resources and previous experience of trustful relations, it seemed that acceptance and accountability were enough to co-create a working alliance with the professional. For persons lacking these resources, trusting a professional was described as a detour on the road to 
accepting a more hopeful image of themselves. Accepting the professional's hope could be a way to start to integrate the possibility of a more positive sense of self and even of a different and better life.

According to the professionals' experiences, once trust in them had been established, it could be moved to the person, thus creating a basis for further developments:

I have met persons who told me: "There is nothing left for me. It is over", and I answered that "there is always hope". Then I have met them sober and drug-free. They had moved on. They told me: "You came to me and said that there still was hope for me. Then something happened!" It was important that there was someone who believed in them and remained there (IP2).

A difficult balancing act was between realistic and utopian hope. In one sense, all hope might be considered as utopic, but trusting a professional figure and sharing his/her hope and co-producing changes might transform this hope from utopic to realistic:

I think that they start to see you as a good sounding board and they begin to trust you. I propose a realistic hope to them. Otherwise, they would see through it; they are conscious of their problems (IP3).

Building trust and hope might also be said to start from a naive position. Against the collected stories of failures and the often pessimistic image about the future for persons with double troubles, the professional puts his/her faith in the person's capacity and in a common project, even proposing to base their cooperation on the person's wishes and will, sometimes acting against the structured interventions usually proposed by their agencies:

You have to listen to the person's needs. You may look at their clinical journal, but you have to listen to them and take it at their pace, check off, and get their confirmation. That's how you get their trust (IP11).

The trust the professional showed in the person might result in trust in the professional. Such a trust had to be associated with common actions resulting in sometimes small but palpable changes for the person. The process described in the interviews contained stages, such as relying on somebody else who seems to accept and respect you, agency, meaning the experience that one might influence one's own life according to one's own agenda and, as a consequence, the experience of well-being, and finally a bourgeoning trust in one's capacity and future; in oneself as a person. The trust placed in the professional could be compared to a crutch helping the person to progress towards achievements that were not even imaginable.

\section{Trust in themselves}

Repeated experiences that the trust conferred on the professional might not lead to betrayal but, on the contrary, the co-creation of improvements in one's life seemed to impact on the person's sense of self. Experiences of concrete actions leading to tangible changes nurtured the person's impression that he/she might be able to influence his/her life:

When it starts to move forward in the right direction - often it is about a small increase in the person's trust in his own ability. To find some confidence. I think we work to help our clients to get in touch with some kind of trust in themselves (IP5).

Professionals described turning points, where the person started taking their own initiatives as a result of an emerging trust in their own capacity:

It doesn't always happen, but if they have developed trust, then they might relax a bit and be more open. Most have a negative sense of self; a great handicap. When they feel that we see them, then something happens. They feel secure and become more honest and dare to show themselves. That liberates a lot of energy (IP15).

The development of an improved sense of self - experiencing oneself as an agent able to make choices and transform these choices in successful actions, accomplishments and well-being - was described as a prerequisite for a sustained recovery process:

He developed a positive sense of self and self-confidence. He felt that he could do things others appreciated. To feel good influences the sense of self. It is a feeling that motivates one to hold on and not forget that there is an alternative to complete darkness. It means to get back a belief about what one is able to do (IP4). 
The last part in this process described by the interviewees was when persons, based on their trust in themselves, started to give something back; building a sense of reciprocity and re-establishing the "user" as a person.

When they feel that they have something to contribute, that they are able to give something to others, to the community. That they are needed. It can be just by washing the plates, or if they like dogs, to help at a day center for dogs. That they have something to give (IP15).

\section{Managing a fragmentized and fragmentizing organisation}

Professionals made efforts to create helpful relationships in an organisational context. This context was constituted of their own organisations and of a network of organisations responding to different aspects of the persons' needs and problems. They mentioned that this organisational context could support but also counteract their efforts.

\section{Continuity and time}

A recurring criticism concerned the different organisations' equation of delimited time with efficacy. On the contrary, having time was presented as one of the main resources needed to build trust. "Trust demands time, it cannot grow in a couple of weeks" (IP15).

Time had two different aspects. The first concerned irregular time; the possibility to dedicate much time to a person in specific situations. The second concerned continuous time; the possibility to build a relationship over time. The first aspect was connected to accountability at the beginning of the relationship, but both made possible reciprocal knowledge between the user and the professional, facilitating the growth and maintenance of trust and thus of positive development.

Those time-related conditions could come into conflict with the well-defined, goal-related demands for quick results from the organisational contexts that the user and the professional were in:

It has to take its time. Usually there is this requirement from different agencies that one has to progress.

They ask "How far have you got?" It has to go quick [...]. But in reality it takes time (IP2).

Having time over a longer period was experienced as a basis for relational continuity, and continuity was experienced as a basis for trust-building.

Several interviewees reported that the traditional connection between time and trust had recently gone through a radical change in some agencies' way of working. This change reflected developments on a societal level, going from "zero tolerance" to a concern more with harm reduction:

There is a system-shift going on. Now it is possible to talk about harm reduction. Here, we think that people many times have made themselves impossible so they would be thrown out when they had a relapse. We see it as a part of the process and continue with our relationship. We give several chances, and this is very important for this group (IP15).

The professionals described increased possibilities to continue to work with persons even when they had relapses or when they were still using drugs during their contact with social and health agencies. Traditionally such situations led immediately to the interruption of the relationship and, thus, to a loss of the gains obtained in its framework. It seemed now that there was a growing awareness of the counter-productivity of such a way of working.

Some even hypothesised that the possibility to stay connected to the services, independently of relapses or of on-going substance use outside the services, could lead to a reduction in substance use:

Previously we had a requirement that newcomers had to be sober for three months before coming to us. The result was that very few were admitted here. It was too big a step to take for them. Now we accept persons with an on-going addiction, even if we have a zero tolerance for use in our facility. Sometimes we have to ask persons to leave, but they are always welcomed back. We have seen that if one is welcomed back, the abuse diminishes. Some do not drink at all the day before they come to us. Others have told me that they drink less, now that they can come to our place (IP8). 
This experience-based focus on time as an important instrument in professional work was common for many of the interviewees, but not for all agencies they worked in.

\section{Split organisations}

The division of responsibilities between diverse organisations with different aims, responsibilities and cultures created difficulties for persons in their recovery journeys and entailed a need for cooperation between services with different agendas. Professionals described their roles as helping the person to get in touch with different services, helping them in their interaction with services and initiating and participating in coordination meetings.

Coordinating the efforts from different services was also a way to develop trust for professionals if they resulted in tangible improvements for the person. Several stressed their role of arguing for the person's agenda against the collaborating agencies' routines and preoccupations:

You become a spokesman for the person in different instances. Low self-confidence is a common factor, so it is important that they dare to trust me. Many have an earlier experience of betrayal. Trust is created through being there, taking time, listening and being careful to see that things go according to their plans (IP10).

Working to create a collaborating network of services was important at different times in the recovery journey, and at the very beginning, to secure the person's basic rights.

\section{Structures and beyond}

Another aspect of the organisations was their structuring character:

This is a sheltered housing and we do have a clear daily routine 'and structures, which are helpful for many. Those who live here get help to find a daily routine, food and medicine in a drug-free environment.

They have to regularly be tested for drugs/alcohol [...] They say that the structure is helping them (IP12).

Thus, the structure could be presented as a positive context for persons that had lived a dis-organised life for a long time. However, it could also be understood as a rigid apparatus not taking into account the individuals' diversity. This indicated the necessity to manage the contradictions between different organisations' structures, general rules and quest for clarity, and everyday life's need for individual adaptation, approximation and improvisation:

The possibility to work in a more open, not so rigid way and to go a little bit beyond the rules and regulations would be important and give other possibilities (IP7).

Far away from rigid solutions directed at all persons fulfilling certain diagnostic criteria, the professionals pointed out the importance of individualised interventions based on the different persons' backgrounds, life histories and present social situations. In this perspective, the same aspect of an organisation and its rules and routines could at sometimes function as helping or hindering components of the persons' recovery journey. The role of the professional was described as both to maintain and to adapt these rules and routines and sometime supersede them, depending on the requirements of each specific person and situation.

\section{The importance of societal conditions for improvement}

We offer a lot of community-based interventions, which means that it is important that the patient feels safe, that there is a social stability around the patient (IP3).

Connected to the need to manage a fragmentized organisation, professionals mentioned that their efforts to create optimal conditions for a recovery process might be influenced by societal conditions resulting from political decisions. Two aspects dominated this theme; financial strain and housing:

Necessary conditions are decent housing and an acceptable financial situation. We have to help a lot of them with the social services and with practical questions, because their situation is chaotic. It is difficult to talk about their AOD problems before they have achieved some basic stability in their life; a roof over their head and food on the table (IP5).

Basic living conditions were described both as prerequisite for successful professional interventions and as a necessary basis for maintenance of the recovery process. Not having to 
worry about finding a decent place to live, a home, and money to manage everyday life expenses gave more energy for the fight against AOD and mental health problems. The experiences recounted by the professionals reflected a readiness to work with these issues, but also difficulties to secure even such a basic start point.

\section{Discussion}

The aim of this study was to collect and analyse experience-based knowledge from professionals working for dual recovery, about their own helping interventions. Our findings pointed out the importance of combining interventions around: the lack of trust that often develops in a life characterised by mental health and AOD problems, the need to counteract problems created by the different aims, agendas and cultures of diverse agencies, and societal dis-functions regarding the material basis for a normal everyday life for persons in recovery.

Our findings confirm the results from other studies (Brekke et al., 2017; Cruce et al., 2012; Ness et al., 2014; Skogens and von Greiff, 2014) about the importance of a co-productive approach based on the person's agenda, and of improving their material conditions (housing and financial strain) to initiate and secure a recovery process. Our findings also stress the importance of developing a positive sense of self, based on experiences of acceptance and agency.

A specific finding was how the professionals differentiated the persons according to their previous experiences of trustful relations and the current availability of resources from their social network. To contribute to a recovery process, professionals needed to adapt their ways of being and helping to these prerequisites. In this discussion, we will relate these findings to the concept of recovery capital (RC) developed both in the field of AOD (Cloud and Granfield, 2008) and of mental health problems (Tew, 2013).

\section{Recovery capital}

There are different definitions and ways to operationalise RC (Hennesssy, 2017). Cloud and Granfield (2008) have defined RC as "a body of resources that can be accumulated or exhausted". Tew (2013) has proposed five types of RC; economic (money at one's disposal), social (resources in one's social network), identity (relations with significant others), personal or mental capital (coping and ways of seeing oneself) and relationship capital (the quality of close relationships). The impact of $\mathrm{RC}$ depends on both its quantity and its spread. Tew also argued that having access to different forms of capital was not enough to start and maintain a recovery process. The decisive factor was the persons' own motivation to start and pursue this uncertain and demanding journey.

The professionals we interviewed did not use the concept of RC, but they stressed its different forms in their accounts, i.e. the importance of a home and access to enough economical resources to live a decent life. These forms of economic and social capital could exist from the start or be acquired through the help of a social network. If the person lacked these prerequisites, then the work of the professional was, in collaboration with the person, to create this basis for recovery (personal capital).

In working together according to the person's agenda, the interviewees also stressed the importance of maintaining, or restoring the person's sense of self beyond his/her identity as a "drug addict" and a "mental patient" (personal capital). Through "affirmative social experiences" (Tew, 2013) professionals and persons worked first to create trust in the professionals as carriers of hope that change was possible (relationship capital), developing tangible changes resulting in a bourgeoning sense of trust for the person in him/herself (identity capital). This process might strengthen the motivation mentioned by Tew (2013), for persons lacking trust in their own capacity at the beginning of the process. Thus, the professional might function as a "surrogate hope" for a period of time (Deegan, 1988). This lack of trust and hope, present in persons with a low RC, was described by the professionals as based on previous experiences (relationship capital), but also on repeated experiences of stigmatisation (identity capital).

Building the person's trust in the professional was described as a step in the creation of relationship capital, defined by Tew (2013) as "a social environment that offers recognition and acceptance" (p. 369). 


\section{Trust, motivation and $R C$}

Even if the experiences and practices described are in accordance with the findings of other studies (Ljungberg et al., 2015; Ness et al., 2015; Skogens and von Greiff, 2014), the professionals in this study introduced a somewhat more complex picture of the process of (re)creating trust.

As already mentioned, Tew added that the disposable capital must be set in motion by the individuals' will to change. Motivation was not either present or absent. Studies of recovery show that motivation varies over time (Strauss, 1989; Topor, 2012).

The amount and distribution of different forms of RC conditioned the professionals' interventions. Depending on the person's experiences and actual social situation, professionals made a difference between persons with a high or a low RC at their disposal. Persons with a low RC were characterised by a low sense of self, based on the lack of trustful experiences in their life and the fragility or absence of a social network willing to offer its resources. Persons with a higher RC often experienced trustful relations and had a social network to (re)connect to.

In both cases, the professionals described work based on acceptance and mutual trust and co-production with a growing space for the persons' agency. But the work with persons with a low RC started by focussing on strengthening the motivation of the person through the provision of experiences of basic trust, first directed towards the professional and second towards the persons' own capacity to influence their life and, finally, to accept themselves as agents. The trust they put in the professionals was part of the co-creation of a basic sense of self and trust in themselves. Their motivation had to be protected as we noticed in two paradoxes formulated by the professionals. They had a deep need for acceptance to maintain their motivation for change, and the professional sometimes had to be the advocate of the agreed actions and fight against the person for changes according to the person's own agenda.

Trust in oneself was a key aspect of a sustained motivation as it was the basis for believing that the person was worth a better life and could even take part in the co-production of this life. Nevertheless, to co-create you need to have somebody you trust, and to trust yourself as able to have a relationship with somebody else.

In recovery research, the sense of self has become of central importance (Davidson and Strauss, 1992; Mancini, 2007) and develops out of an interaction between agency and reflection to integrate the new experiences of being an agent able to produce well-being in the person's identity capital, and planning for the next steps in the recovery process.

For persons with a higher RC the trust in the professional could be characterised as a support to re-discover existing capacities and resources, and to return to a previous experience of agency and a positive sense of self.

\section{Conclusion}

Recovery has been described as a profoundly individual journey (Anthony, 1993). However, like all journeys it is also deeply social, involving other persons and contextual factors both in the direct environment, and at a societal level (Topor et al., 2011). The presence of helpful social networks with different resources but also of basic living conditions (decent housing, money) played a central part in the journey. Persons lacking such resources seem also to lack experience of past and present trustful relationships. For them the co-creation of these resources, together with professionals, also created experiences of reciprocal trust. In its extension these experiences could lead to a more positive sense of the self; that is commonly defined as an important part of a sustain recovery process.

Focussing solely on one level of the professionals' interventions might over-simplify, and thus counteract, the complex work to be done both by the person and by professionals employed to help him/her.

\section{Limitations}

The findings from this study are based on a relatively small sample of professionals, mostly working in social agencies in the Stockholm region. Thus, the collected experiences were biased (social work and welfare country) compared to other professionals' experiences in the same field. 
Keeping these biases in mind, the presented findings might cast a special light on findings from studies done in other contexts.

Individual interviews leave the person outside his/her context. Other studies have worked with focus-group methodologies and thus have included part of the participants' natural context in their prerequisites. On the other hand, the risk with collegial groups might be that deviation from and questioning of the official understanding of one's work and professional duties could be silenced (Le Boutillier et al., 2015).

Further studies should include professionals working in different organisational frames and professionals working in different socio-political contexts.

\section{References}

Anthony, W.A. (1993), "Recovery from mental illness: the guiding vision of the mental health service system in the 1990s", Psychosocial Rehabilitation Journal, Vol. 16, pp. 11-23.

Bellack, A.S. (2006), "Scientific and consumer models of recovery in schizophrenia: concordance, contrast and implications", Schizophrenia Bulletin, Vol. 32 No. 3, pp. 432-42.

Bertaux, D. (1997), Les récits de vie, Nathan, Paris.

Bleuler, E. (1950), Dementia Praecox or the Group of Schizophrenia, International Universities Press, New York, NY.

Blomqvist, J. (1996), "Paths to recovery from substance misuse; change of lifestyle and the role of treatment", Substance Use and Misuse, Vol. 31 No. 13, pp. 1807-52.

Braun, V. and Clarke, V. (2006), "Using thematic analysis in psychology", Qualitative Research in Psychology, Vol. 3 No. 2, pp. 77-101.

Brekke, E., Lien, L., Davidson, L. and Biong, S. (2017), "First-person experiences of recovery in co-occurring mental health and substance use conditions", Advances in Dual Diagnosis, Vol. 10 No. 1, pp. 13-24.

Cloud, W. and Granfield, R. (2008), "Conceptualizing recovery capital: expansion of a theoretical concept", Substance Use \& Misuse, Vol. 43 Nos 12-13, pp. 1971-86.

Cruce, G., Öjehagen, A. and Nordström, M. (2012), "Recovery-promoting care as experienced by persons with severe mental illness and substance misuse", International Journal of Mental Health Addiction, Vol. 10 No. 5, pp. 660-9.

Davidson, L. and Strauss, J.S. (1992), "Sense of self in recovery from severe mental illness", British Journal of Medical Psychology, Vol. 65, pp. 131-45.

Davidson, L. and White, W. (2007), "The concept of recovery as an organizing principle for integrating mental health and addiction services", Journal of Behavioral Health Services and Research, Vol. 34 No. 2, pp. 109-20.

Davidson, L., Andres-Hyman, R., Tondora, J., Fry, J. and Kirk, T. (2008), "From "double trouble" to "dual recovery": integrating models of recovery in addiction and mental health", Journal of Dual Diagnosis, Vol. 4 No. 3, pp. 273-90.

Deegan, P.E. (1988), "Recovery: the lived experience of rehabilitation", Psychosocial Rehabilitation Journal, Vol. 11 No. 4, pp. 11-19.

Denhov, A. and Topor, A. (2012), "The components of helping relationships with professionals in psychiatry: users' perspective”, International Journal of Social Psychiatry, Vol. 55 No. 4, pp. 417-24.

Elison, S., Weston, S., Dugdale, S., Ward, J. and Davies, G. (2016), "A qualitative exploration of U.K. prisoners' experiences of substance misuse and mental health difficulties, and the breaking free health and justice interventions", Journal of Drug Issues, Vol. 46 No. 3, pp. 198-215.

Farkas, M. (2007), "The vision of recovery today: what it is and what it means for services", World Psychiatry, Vol. 2 No. 2, pp. 68-74.

Hennesssy, E.A. (2017), "Recovery capital: a systematic review of the literature", Addiction Research \& Theory, Vol. 25 No. 5, pp. 349-60.

Hipolito, M.M.S., Carpenter-Song, E. and Whitley, R. (2011), "Meaning of recovery from the perspective of people with dual diagnosis", Journal of Dual Diagnosis, Vol. 7 No. 3, pp. 141-9.

Le Boutillier, C., Slade, M., Lawrence, V., Bird, V.J., Chandler, R., Farkas, M.X.X.X. and Leamy, M. (2015), "Competing priorities: staff perspectives on supporting recovery", Adm Policy Ment Health, Vol. 42 No. 4, pp. 429-38. 
Ljungberg, A., Denhov, A. and Topor, A. (2015), "The art of helpful relationships with professionals: a metaethnography of the perspective of persons with severe mental illness”, Psychiatric Quarterly, Vol. 86 No. 4, pp. 471-95.

Mancini, M.A. (2007), "The role of self-efficacy in recovery from serious psychiatric disabilities", Qualitative Social Work, Vol. 6 No.1, pp. 49-74.

Ness, O., Borg, M. and Davidson, L. (2014), "Facilitators and barriers in dual recovery: a literature review of first-person perspectives", Advances in Dual Diagnosis, Vol. 7 No. 3, pp. 107-17.

Ness, O., Kvello, Ø., Borg, M., Semb, R. and Davidson, L. (2017), “'Sorting things out together': young adults' experiences of collaborative practices in mental health and substance use care", American Journal of Psychiatric Rehabilitation, Vol. 20, pp. 126-42.

Orford, J., Hodgson, R., Copello, A., John, B., Smith, M., Black, R., Fryer, K., Handforth, L., Alwyn, T., Kerr, C., Thistlethwaite, G., Slegg, G. and UKATT Research Team (2006), 'The clients' perspective on change during treatment for an alcohol problem: qualitative analysis of follow-up interviews in the UK alcohol treatment trial", Addiction, Vol. 101, pp. 60-8.

Sælør, K.T., Ness, O., Borg, M. and Biong, S. (2015), "You never know what's around the next corner: exploring practitioners' hope inspiring practices”, Advances in Dual Diagnosis, Vol. 8 No. 3, pp. 141-52.

Skogens, L. and von Greiff, N. (2014), "Recovery capital in the process of change-differences and similarities between groups of clients treated for alcohol or drug problems”, European Journal of Social Work, Vol. 17 No. 1, pp. 58-73.

Strauss, J.S. (1989), "Mediating processes in schizophrenia-towards a new dynamic psychiatry", British Journal of Psychiatry, Vol. 155 No. S5, pp. 22-8.

Tew, J. (2013), "Recovery capital: what enables a sustainable recovery from mental health difficulties?", European Journal of Social Work, Vol. 16 No. 3, pp. 360-74.

Topor, A. (2012), Managing the Contradictions-Recovery from Severe Mental Illness, LAP Lambert Academic Publishing AG \& Co. KG, Saarbrücken.

Topor, A., Borg, M., Di Girolamo, S. and Davidson, L. (2011), "Not just an individual journey: social aspects of recovery”, International Journal of Social Psychiatry, Vol. 57 No. 1, pp. 90-9.

von Greiff, N. and Skogens, L. (2014), "The mechanism of treatment - client and treatment staff perspectives of change during treatment for alcohol problems”, Nordic Social Work Research, Vol. 4 No. 2, pp. 129-43.

Warner, R. (1985/2004), Recovery from Schizophrenia-Psychiatry and Political Economy, 3th ed., Brunner Routledge, New York, NY.

Watson, D.P. and Rollins, A.L. (2015), "The meaning of recovery from co-occurring disorder: views from consumers and staff members living and working in housing first programming", International Journal of Mental Health and Addiction, Vol. 13 No. 5, pp. 635-49.

\section{Further reading}

Frank, D.M. and Davidson, L. (2014), "The central role of self-esteem for persons with psychosis", The Humanistic Psychologist, Vol. 42 No. 1, pp. 24-34.

Harding, C. and Keller, A. (1998), "Long-term outcome of social functioning", in Mueser, K. and Tarrier, N. (Eds), Handbook of Social Functioning in Schizophrenia, Allyn and Bacom, Boston, MA, pp. 134-48.

Laudet, A.B. (2007), "What does recovery mean to you? Lessons from the recovery experience for research and practice", Community Mental Health Journal, Vol. 36 No. 3, pp. 457-76.

\section{Corresponding author}

Alain Topor can be contacted at: alain.topor@socarb.su.se

For instructions on how to order reprints of this article, please visit our website:

www.emeraldgrouppublishing.com/licensing/reprints.htm

Or contact us for further details: permissions@emeraldinsight.com 